\title{
Perancangan Sistem Informasi Stok Onderdil Kendaraan Tronton Tangki Pada Zetka Inc Group berbasis Java"
}

\author{
Sandy Nur Fajar ${ }^{1}$, Muhamad Irsan ${ }^{2}$, dan Retno Nengsih ${ }^{3}$ \\ $1,2,3$ Universitas Indraprasta PGRI \\ Jl. Raya Tengah No.80, RT.6/RW.1, Kel. Gedong, Kec. Pasar Rebo \\ Kota Jakarta Timur, Daerah Istimewa Jakarta 13760 \\ Email : sandifajar12@gmail.com, atstairway@gmail.com,retnonengsih3dharma@gmail.com
}

\begin{abstract}
Abstrak - Dengan adanya sistem stok onderdil ini, yang diharapkan akan memudahkan untuk pencatatan stok serta pencetakan laporan. Pencatatan pemeliharaan kendaraan dilakukan oleh Divisi Procurement. Semua pencatatan suku cadang mobil Truk Kapsul dan Dump Truck biasa dicatat di Microsoft Excel oleh tim Procurement dengan baik. Cara kerja tim Procurement tersebut biasanya dilakukan dengan sharing data melalui jaringan lan pada komputer mereka. Untuk pengecekan dan bertukar data biasanya dilakukan dengan sharing data melalui jaringan lan. Tujuan penelitian adalah untuk membuat sistem stok onderdil dengan menggunakan metode SDLC data flow diagram.
\end{abstract}

Kata kunci: Perancangan Aplikasi, Java, mysql, Onderdil, Perusahaan Zetka Inc Group

Abstrak - With this spare parts stock system, it is hoped that it will make it easier for stock recording and report printing. Recording of vehicle maintenance is carried out by the Procurement Division. All records of car spare parts for Capsule Trucks and Dump Trucks are properly recorded in Microsoft Excel by the Procurement team. The way the Procurement team works is usually done by sharing data over a LAN network on their computers. Checking and exchanging data is usually done by sharing data over a LAN network. The purpose of this research is to create a spare parts stock system using the SDLC data flow diagram method.

Keyword: Application Design, java, mysql, Parts, Zetka Inc Group Company

\section{Pendahuluan}

Stok onderdil merupakan salah satu aplikasi yang dibuat untuk pencatatan stok serta pencetakan laporan. Pencatatan pemeliharaan kendaraan dilakukan oleh Divisi Procurement [1]. Semua pencatatan suku cadang mobil Truk Kapsul dan Dump Truck biasa dicatat di Microsoft Excel oleh tim Procurement dengan baik. Cara kerja tim Procurement tersebut biasanya dilakukan dengan sharing data melalui jaringan lan pada komputer mereka. Untuk pengecekan dan bertukar data biasanya dilakukan dengan sharing data melalui jaringan lan. [2]. Salah satu langkah yang bisa diterapkan untuk meningkatkan fungsi stok onderdil adalah dengan menggunakan sistem pengolahan data yang tepat dan cepat. Sistem aplikasi stok onderdil yang dibutuhkan oleh perusahaan nantinya dipergunakan untuk tujuan pencatatan stok, pencetakan laporan.

Akan tetapi jika menggunakan [3] Microsoft Excel tidak bisa digunakan bersama dalam waktu bersamaan, hanya satu orang saja yang dapat mengubah dan lainnya hanya bisa melihat saja data tersebut. Oleh karena itu, tujuan untuk membangun sistem aplikasi stok onderdil kendaraan berbasis Java pada Zetka Inc Group yang diharapkan mampu untuk memudahkan dan mengamankan data stok onderdil tersebut bagi divisi tersebut, serta mampu meningkatkan kinerja bagi para karyawan kantor itu sendiri. Baik dalam pendataan kendaraan, pencatatan onderdil kendaraan, serta pemakaian onderdil kendaraan.

\section{Tinjauan Pustaka}

a. Perancangan

Perencananaan suatu sistem yang menyangkut berbagai rancangan sehingga akan menghasilkan sistem yang sesuai dengan hasil dari tahap analisa system yang kita buat[4].

b. Sistem

Sistem yaitu komponen yang saling berhubungan dan saling berinteraksi satu sama lain untuk dimana sitem yang biasanya terbagi dalam sub sistem yang lebih kecil untuk mendukung sistem yang lebih besar [5].

c. Diagram Alir Data

Data Flow Diagram yang grafik menggambarkan aliran informasi dan transformasi yang diaplikasikan sebagai data yang mengatur dari masukan (Input) dan keluar (Ouput)[6].

d. Mysql

MySQL server basis data yang mampu menerima dan mengirimkan data dengan cepat menggunakan 
perintah-perintah SQL[7].

e. Java

Java dapat dijalankan diberbagai computer [8]. Java berdiri disebuah mesin yang diberinama Java Virtual Machine (JVM).

f. Netbeans

Netbeans open source yang sering kali diasosiasikan dengan Java [9]. Akan tetapi IDE untuk membuat proyek-proyek Java saja, melainkan juga proyek seperti web service.

\section{Metode Penelitian}

Metode penelitian yang peneliti gunakan untuk mendapatkan informasi serta data-data yang diperlukan yaitu menggunakan metode deskriptif dengan tujuan untuk mendapatkan data secara detail, mendalam, dan juga aktual.

Maka peneliti melakukan metode pengumpulan data antara lain:

1. Metode observasi (Pengamatan langsung)

Peneliti dengancara pengamatan langsung kelapangan serta mengamati sistem yang sedang berjalan.

2. Metode interview (Wawancara)

Peneliti melakukan tanya jawab kepada kepala perpustakaan, yang berkaitan dengan masalah agar dapat di pecahkan sehingga memperoleh data-data yang benar-benar akurat.

3. Metode Studi Kepustakaan (Literature)

Metode pengummpulan data yaitu mempelajari literature baik berupa dokumen tertulis dan berupa gambar serta mengambil teori-teori yang berhubungan dengan judul penelitian ini.

\section{Hasil dan Pembahasan}

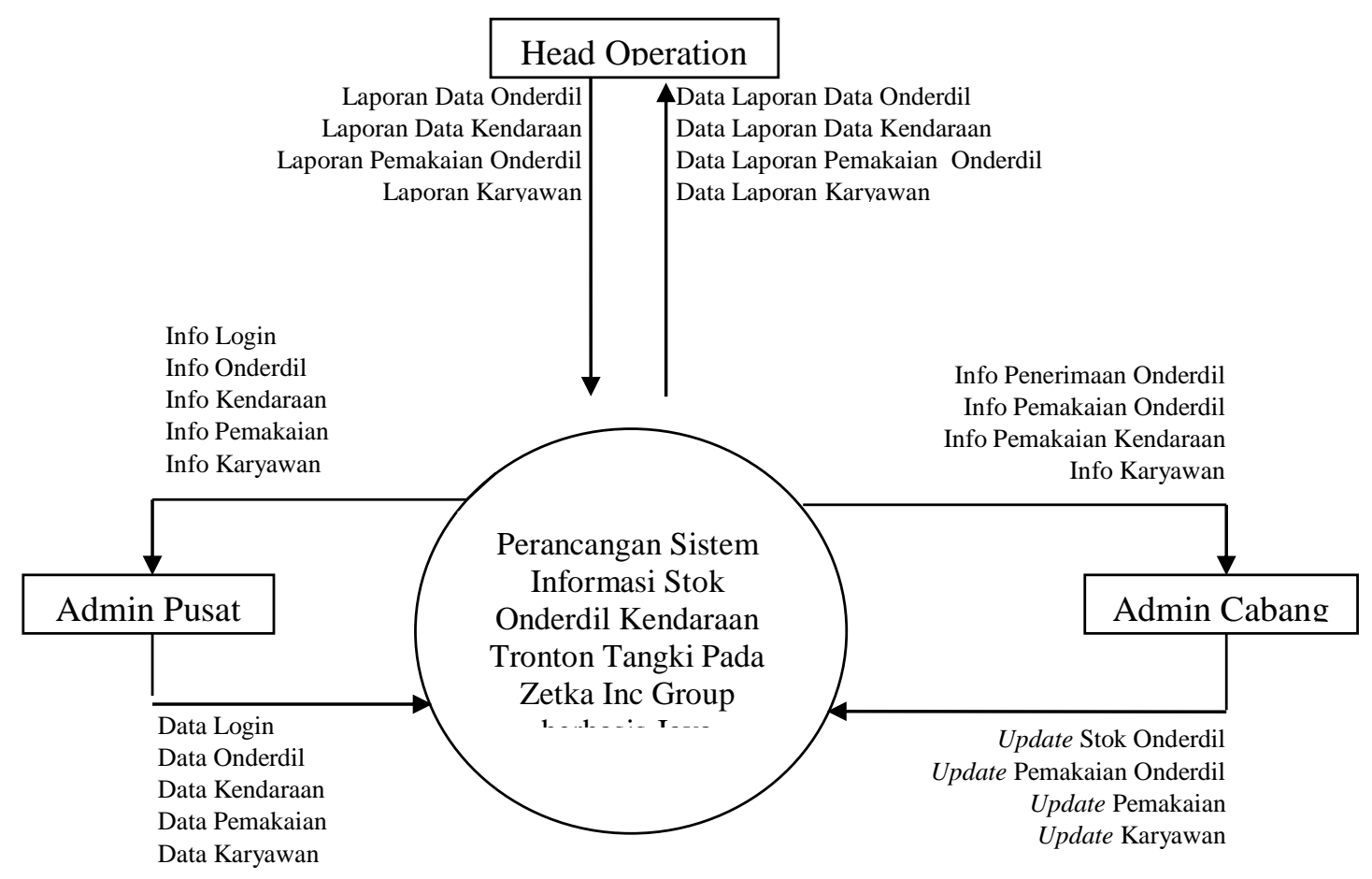

Gambar 1. Diagram Konteks Yang Diusulkan 


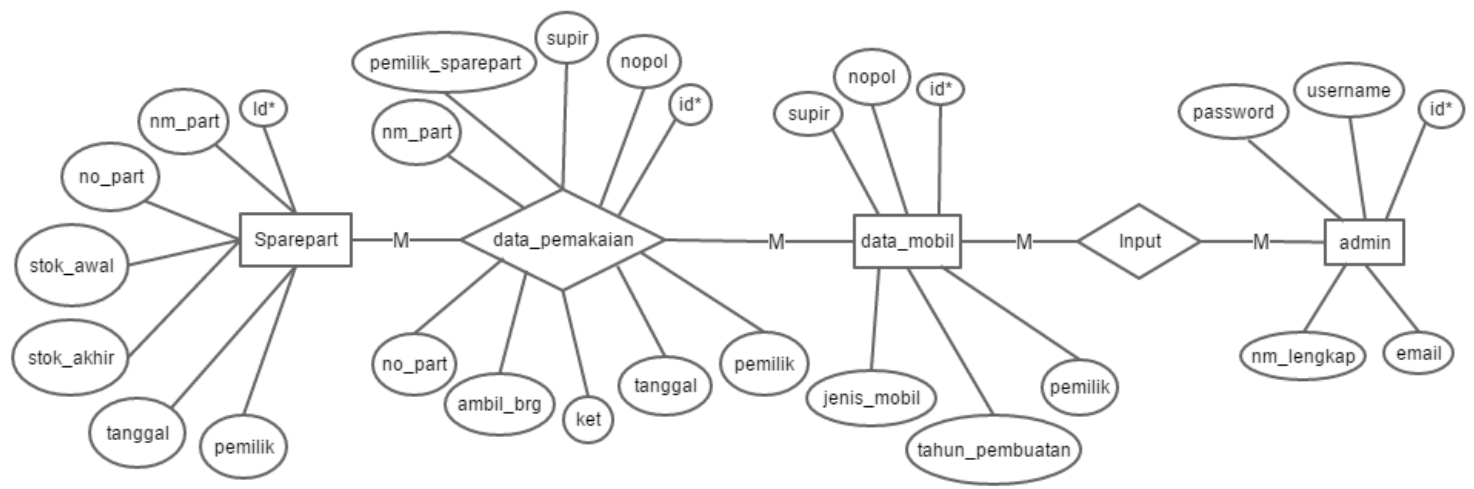

Gambar 2. Entity Relationship Diagram (ERD)

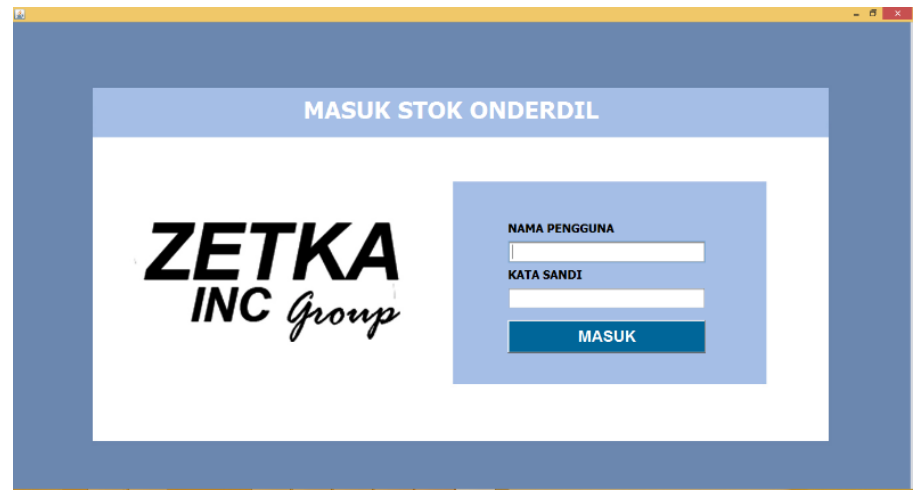

Gambar 3. Tampilan Layar Login

Layar di atas merupakan tampilan login pada aplikasi stok onderdil kendaraan pada Zetka Inc Group, tampilan ini terdapat pada awal program. Tampilan untuk karyawan dan superadmin harus login terlebih dahulu untuk mengakses data onderdil kendaraan.

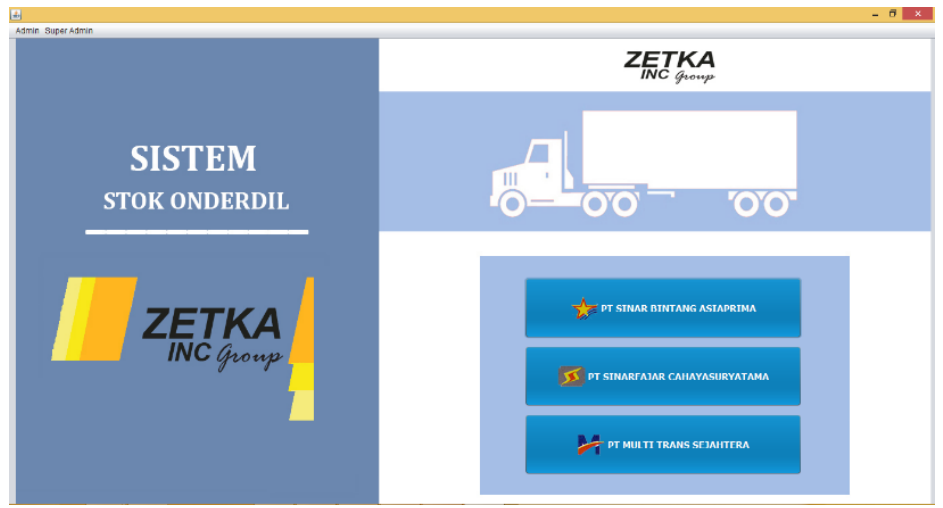

Gambar 4. Tampilan Layar Menu Perusahaan

Layar di atas merupakan tampilan pada menu perusahaan, di mana pada menu ini terdapat 3 pilihan perusahaan dengan jenis kendaraan yang berbeda sesuai dengan kebutuhannya. 


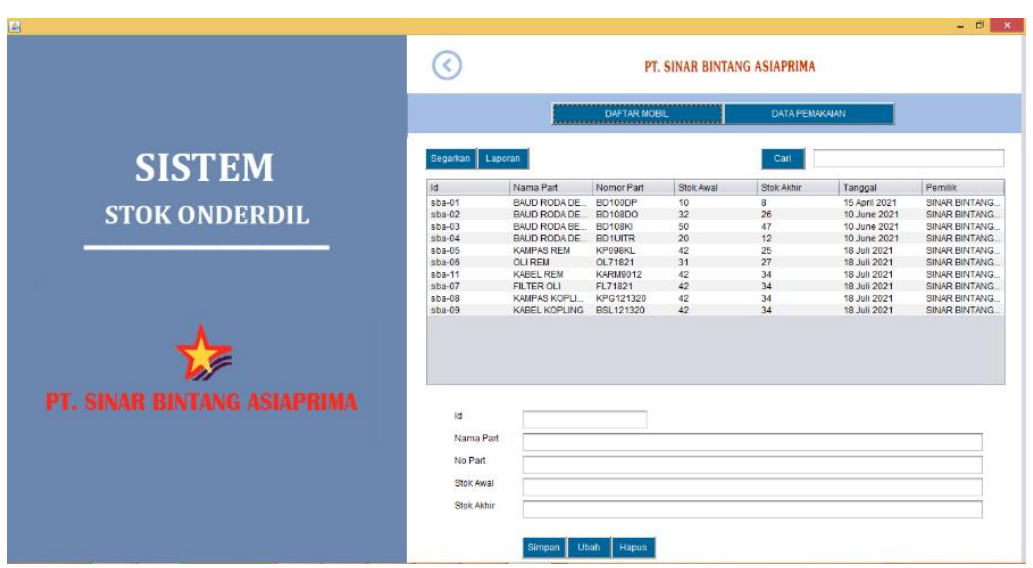

Gambar 5. Tampilan Data Stok Onderdil

Layar di atas merupakan tampilan pada data stok onderdil yang terdapat tabel untuk melakukan penginputan stok onderdil. Menu ini hanya untuk update stock onderdil kendaraan.

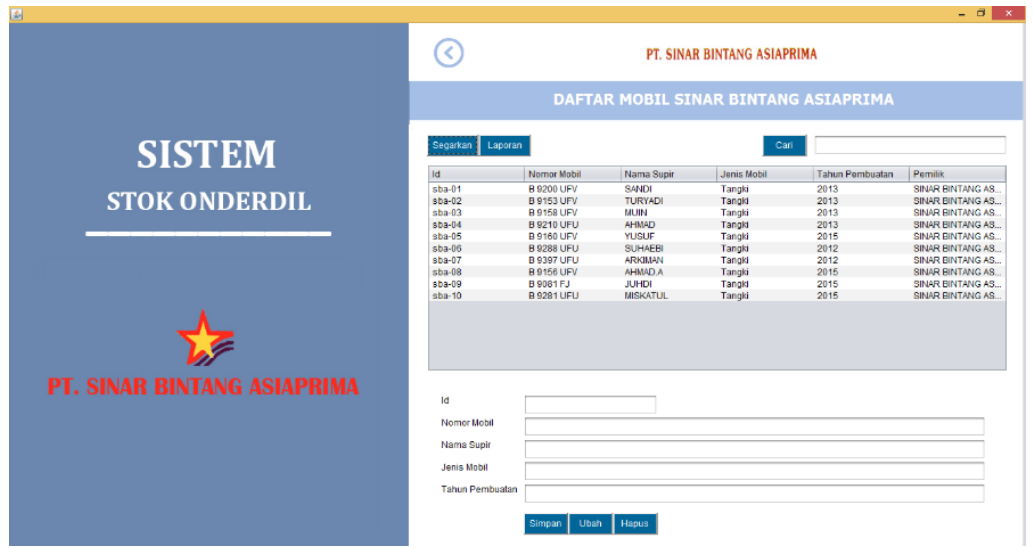

Gambar 6. Tampilan Data Kendaraan

Layar di atas merupakan tampilan pada data kendaraan yang terdapat tabel untuk input jenis kendaraan dan sopir yang menggunakannya. Menu ini hanya untuk input data kendaraan.

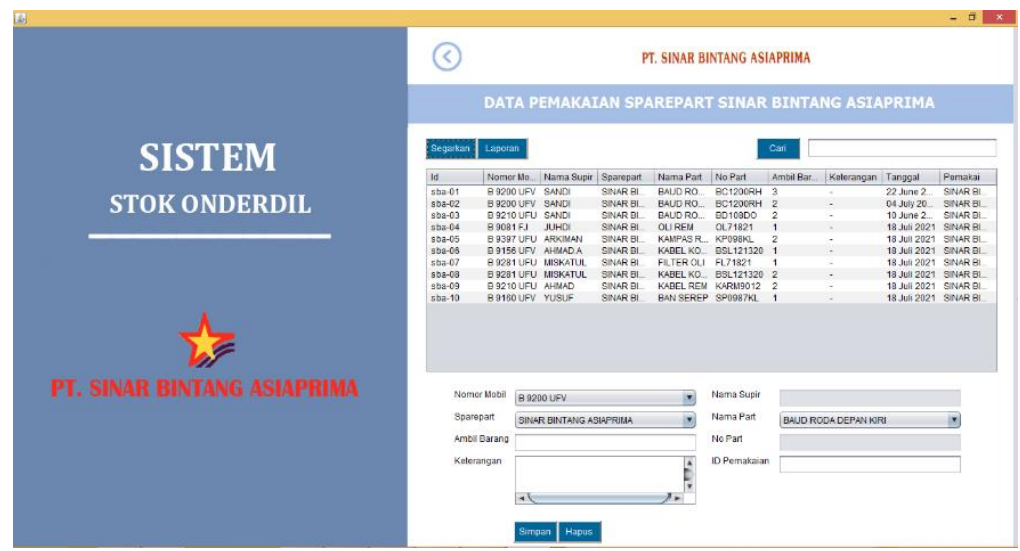

Gambar 7. Tampilan Data Pemakaian

Layar di atas merupakan tampilan pada data pemakaian onderdil kendaraan yang terdapat tabel untuk melihat jenis kendaraan dan nama onderdil yang dipakai pada saat sopir mengajukan perbaikan. Menu ini hanya untuk input data pemakaian onderdil kendaraan. 


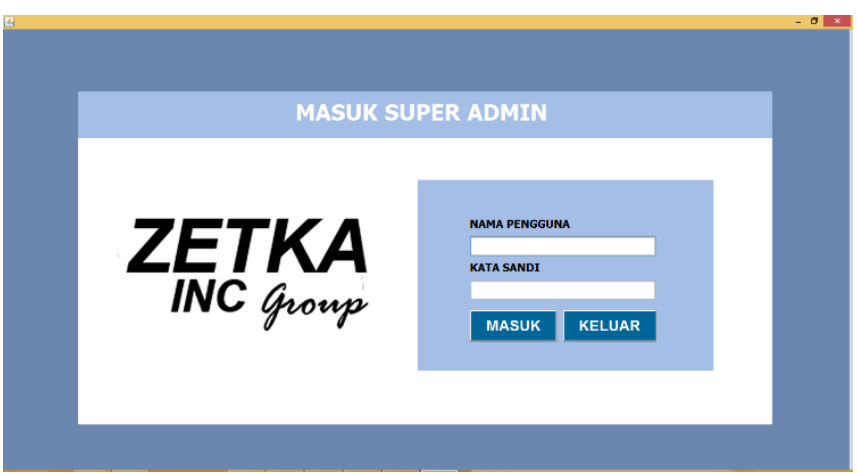

Gambar 8. Tampilan Login Menu Super Admin

Layar di atas merupakan tampilan login untuk super admin melakukan penginputan akses data karyawan. Hanya super admin yang bisa masuk dan membuat username dan password untuk karyawan.

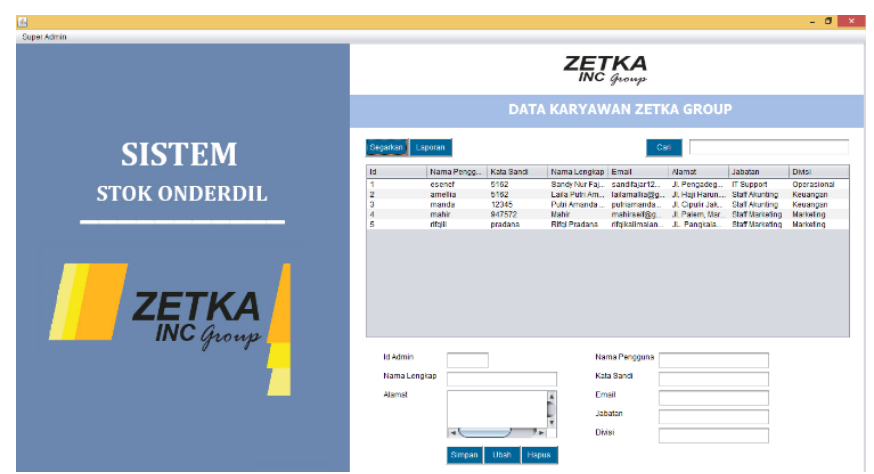

Gambar 9. Tampilan Data Karyawan

Layar di atas merupakan tampilan data karyawan yang terdapat tabel untuk membuat username dan password karyawan agar bisa login ke aplikasi stok onderdil kendaraan.

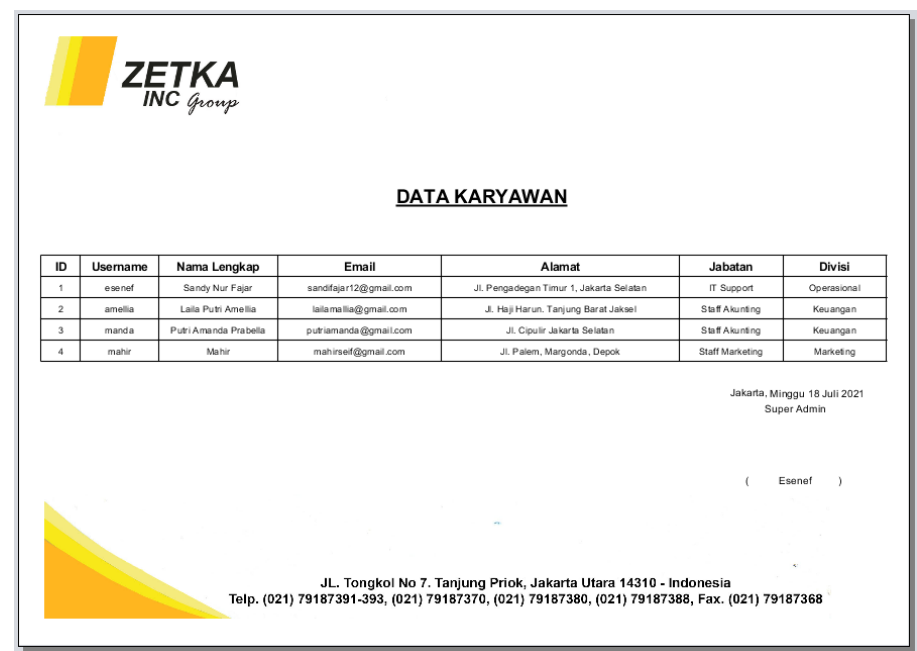

Gambar 10. Tampilan Laporan Data Karyawan 
P-ISSN 2620-8342

E-ISSN 2621-3052

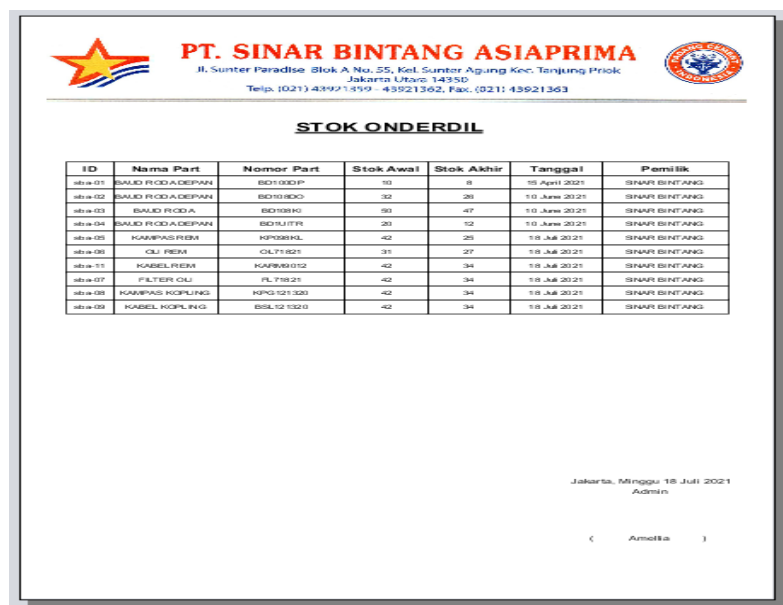

Gambar 11. Tampilan Laporan Data Stok Onderdil PT. Sinar Bintang Asiaprima

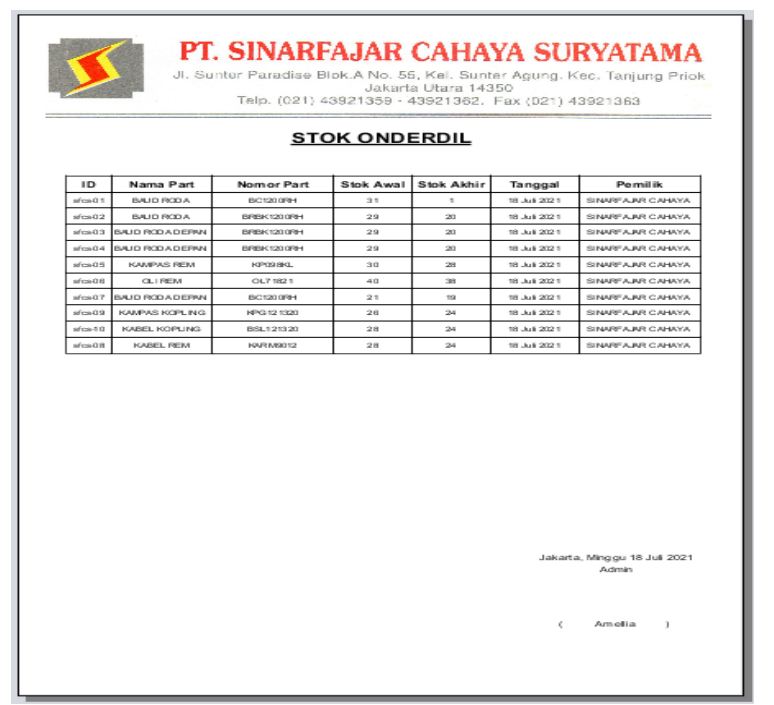

Gambar 12. Tampilan Laporan Data Stok Onderdil PT. Sinarfajar Cahaya Suryatama 


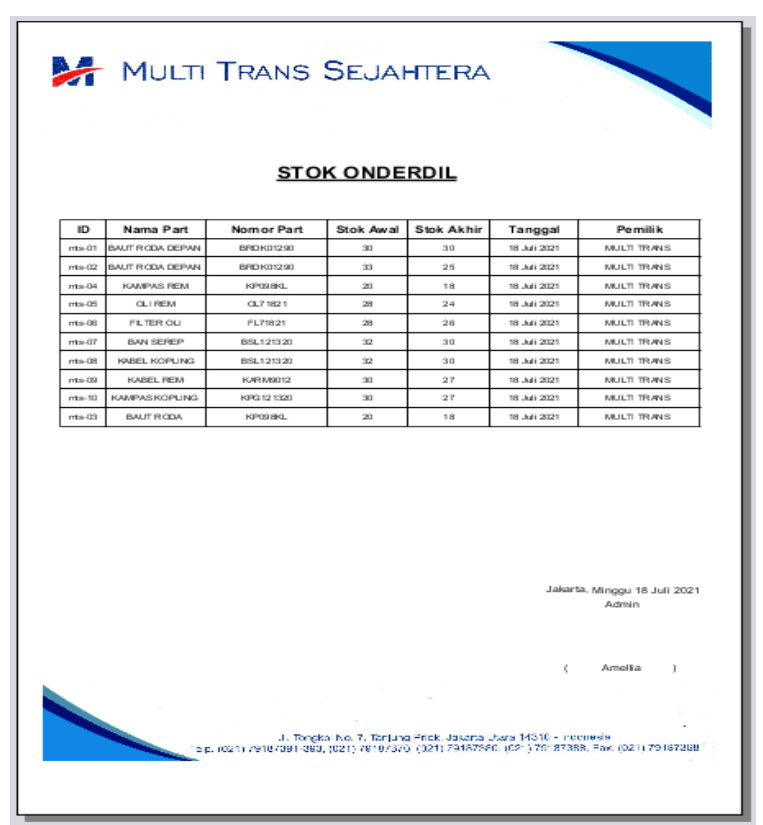

Gambar 13. Tampilan Laporan Data Stok Onderdil PT. Multi Trans Sejahtera

\section{Kesimpulan}

Dengan sistem ini, dapat membantu menyediakan laporan stok onderdil kepada pimpinan secara periodik dan berkesinambungan, menghasilkan data yang cepat dan akurat melalui sistem komputerisasi yang lebih efisien dibandingkan dengan sistem manual untuk mendukung kinerja perusahaan

\section{Daftar Pustaka}

[1] Al-Bahra bin Ladjamudin. 2013. Analisis dan Desain Sistem Informasi.

[2] Hutahaean, Jeperson. 2015. Konsep Sistem Informasi. Yogyakarta: Deeppublish. Jakarta: PT.Bumi Akasara.

[3] Mulyani, Sri. 2016. Sistem Informasi manajemen Rumah Sakit, Analisis dan Perancangan. Bandung: Abdi Sistematika.

[4] Munir. 2011. Pemrograman Basis Data Berbasis web Menggunakan PHP\&MySQL. Bangkalan: Grahara ilmu.

[5] Nofriadi. 2015. Pengertian Netbeans. Jakarta: Andi Offset.

[6] Rosa A.S dan Shalahudin. M. 2015. Rekayasa Perangkat Lunak Terstruktur dan Berorientasi Objek. Bandung: Informatika.

[7] Subtari. 2012. Konsep Sistem Informasi. Jakarta: Andi Offset.

[8] Sutarbi, Tata. 2012. Konsep Dasar Informasi. Andi. Yogyakarta.

[9] Sutarman. 2012. Buku Pengantar Teknologi Informasi. Jakarta: Bumi Aksara.

[10] Richard F, Neuschel. 2011. Sistem Informasi Akuntansi.

[11] Raymond Mcleod Jr. 2012. Sistem Informasi Manajemen. Jakarta : Salemba Empat.

[12] Bernard, S. A. (2012). An Introduction to Enterprise Architecture. Bloomington: AuthorHouse.

[13] Lucas. 2015. Pengertian Sistem Informasi.

[14] Arief M Rudianto. 2011. Pemrograman Web Dinamis menggunakan PHP dan MySQL. C.V ANDI OFFSET. Yogyakarta.

[15] Kurniawan, Hendra, Eri Mardiani, Nur Rahmansyah. 2011. Aplikasi Inventory menggunakan Java NetBeans,XAMPPP, dan iReport. PT Elex Media Komputindo. Jakarta.

[16] T. Hani Handoko. 2015. Manajemen, Edisi 2, BPFE, Yogyakarta.

[17] Agus Ristono. 2013. Manajemen Persediaan. Penerbit Graha Ilmu, Yogyakarta. 